\title{
Low ethanol consumption increases insulin sensitivity in Wistar rats
}

D.T. Furuya,

R. Binsack and

U.F. Machado
Departamento de Fisiologia e Biofísica, Instituto de Ciências Biomédicas, Universidade de São Paulo, São Paulo, SP, Brasil

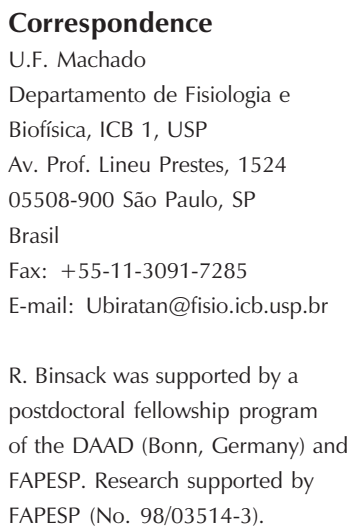

Correspondence

U.F. Machado

Departamento de Fisiologia e

Biofísica, ICB 1, USP

Av. Prof. Lineu Prestes, 1524

05508-900 São Paulo, SP

Brasil

Fax: +55-11-3091-7285

E-mail: Ubiratan@fisio.icb.usp.br

R. Binsack was supported by a postdoctoral fellowship program

of the DAAD (Bonn, Germany) and

FAPESP. Research supported by

FAPESP (No. 98/03514-3).

Received April 18, 2002

Accepted September 17, 2002

\begin{abstract}
Several human studies suggest that light-to-moderate alcohol consumption is associated with enhanced insulin sensitivity, but these studies are not free of conflicting results. To determine if ethanolenhanced insulin sensitivity could be demonstrated in an animal model, male Wistar rats were fed a standard chow diet and received drinking water without (control) or with different ethanol concentrations $(0.5,1.5,3,4.5$ and $7 \%, \mathrm{v} / \mathrm{v})$ for 4 weeks ad libitum. Then, an intravenous insulin tolerance test (IVITT) was performed to determine insulin sensitivity. Among the ethanol groups, only the 3\% ethanol group showed an increase in insulin sensitivity based on the increase of the plasma glucose disappearance rate in the IVITT $(30 \%, \mathrm{P}<0.05)$. In addition, an intravenous glucose tolerance test (IVGTT) was performed in control and 3\% ethanol animals. Insulin sensitivity was confirmed in 3\% ethanol rats based on the reduction of insulin secretion in the IVGTT $(35 \%, \mathrm{P}<0.05)$, despite the same glucose profile. Additionally, the $3 \%$ ethanol treatment did not impair body weight gain or plasma aspartate aminotransferase and alanine aminotransferase activities. Thus, the present study established that 3\% ethanol in the drinking water for 4 weeks in normal rats is a model of increased insulin sensitivity, which can be used for further investigations of the mechanisms involved.
\end{abstract}

Epidemiological evidence from many studies indicates that light-to-moderate drinking of any kind of alcoholic beverage is associated with a reduction in mortality, due primarily to a reduced risk of coronary heart disease (CHD) (1-6). This phenomenon was mainly related to the capability of moderate alcohol levels to lower CHD risk factors like high levels of LDL cholesterol and fibrinogen, and to increase in parallel the levels of cardioprotective HDL cholesterol $(1,7,8)$.

It is not known if ethanol affects those parameters separately or via a common link; however, some studies suggest that light-to-
Key words

- Insulin sensitivity

- Ethanol

- Low ethanol consumption
- Liver glycogen moderate levels of alcohol have a simultaneous influence on many risk parameters by establishing enhanced insulin sensitivity $(9,10)$. This condition is characterized by relatively low plasma insulin levels, which are paradoxically effective enough to increase glucose uptake and to improve the profile of plasma lipids and lipoproteins (10-12). Accordingly, enhanced insulin sensitivity is associated with higher HDL cholesterol and lower triglyceride concentrations. Due to its association with these beneficial effects, Valmadrid et al. (13) recently suggested that alcohol consumption could decrease the risk 
of CHD mortality especially in humans with older-onset diabetes mellitus.

Although some studies indicate that lightto-moderate alcohol intake is associated with enhanced insulin sensitivity, they are not free of conflicting results. For example, while Kiechl et al. (9) showed that plasma insulin levels decreased with higher alcohol consumption, Razay and Heaton (14) found a Ushaped relation, with moderate drinkers having the lowest insulin concentration. That study also described that low-to-moderate drinkers had higher HDL cholesterol and lower triglyceride concentrations than nondrinkers; however, Facchini et al. (10) could only confirm the increase in HDL cholesterol.

Since these controversial observations have not been unraveled to date and the human studies leave some gaps in the complete understanding of the association of light-to-moderate alcohol consumption and insulin sensitivity (15), it was the aim of this study to establish a reliable animal model that will allow more detailed investigations. Male Wistar rats received drinking water without (control) or with different ethanol concentrations $(0.5,1.5,3,4.5$ and $7 \%, \mathrm{v} / \mathrm{v})$ for 4 weeks ad libitum. At the end of this period, an intravenous insulin tolerance test (IVITT) was performed, showing that $3 \%$ ethanol-treated rats were more insulin sensitive. Additionally, the intravenous glucose tolerance test (IVGTT) was performed in control and 3\% ethanol rats to confirm enhanced insulin sensitivity. The data obtained indicate that adding 3\% ethanol to the drinking water indeed enhances insulin sensitivity in Wistar rats without impairing body weight gain or inducing liver injury.

Ethanol ( $99.5 \%$ pure) was obtained from Labsynth (Diadema, SP, Brazil). Insulin (Iolin) was purchased from Biobrás (Montes Claros, MG, Brazil). Glucose (25\%, g/v) was from Merck (Rio de Janeiro, RJ, Brazil).

Male Wistar rats ( $200 \mathrm{~g}$ body weight; 46 animals per cage) were allowed an adapta- tion period of 1-2 weeks with free access to water and food (pellet diet from Nuvilab, Colombo, PR, Brazil). For the subsequent 4 weeks, the rats received drinking water without (control) or with ethanol concentrations of $0.5,1.5,3,4.5$ or $7 \%(\mathrm{v} / \mathrm{v})$, and body weight as well as food and water consumption were recorded. The animals were kept under a 12:12-h light-dark cycle (lights on at 6 am). Daily calorie intake was calculated according to the energy content of the different diets (11.7 kJ per gram chow; $23.4 \mathrm{~kJ}$ per $\mathrm{ml}$ of $100 \%$ ethanol). Before the experiments, the rats were anesthetized by intraperitonal injection of sodium pentobarbital ( $50 \mathrm{mg} / \mathrm{kg}$ body weight). The experiments were carried out around noon. All experimental protocols were approved by the Ethics Committee for Animal Research (CEEA) of the Institute of Biomedical Sciences, University of São Paulo, protocol \#062/2000.

Intravenous insulin tolerance test. Rats were deprived of food for about $2 \mathrm{~h}$ and anesthetized, and then received an intravenous injection of insulin $(0.75 \mathrm{U} / \mathrm{kg}$ body weight). Glucose levels were measured on samples obtained from the tail vein using a glucometer (Precision QID, Medisense, São Paulo, SP, Brazil) at 0, 4, 8, 12 and 16 min after insulin injection. The corresponding 4 to 16 min values were used to calculate the rate constant for plasma glucose disappearance (Kitt) according to the method of Bonora et al. (16).

Intravenous glucose tolerance test. Control and 3\% ethanol-treated rats were fooddeprived for $4 \mathrm{~h}$ and anesthetized and then received an intravenous glucose injection ( $0.75 \mathrm{~g} / 100 \mathrm{~g}$ body weight). Tail venous blood samples were collected immediately before ( $0 \mathrm{~min})$ and at $5,10,15,20$ and $30 \mathrm{~min}$ after injection. The samples were centrifuged $\left(10 \mathrm{~min}, 1,000 \mathrm{~g}, 4^{\circ} \mathrm{C}\right)$ and the plasma obtained was analyzed for glucose and insulin levels. Glucose was determined with a kit from CELM (Barueri, SP, Brazil), and insu- 
lin levels were measured by radioimmunoassay with a kit from DPC (Los Angeles, CA, USA). The data obtained were plotted, and the area under the curve (AUC) was calculated.

Hepatocellular enzyme determination. Control and 3\% ethanol rats were anesthetized, and blood was taken from the inferior vena cava to obtain plasma samples. Aspartate aminotransferase (AST) and alanine aminotransferase (ALT) activities for each plasma sample were measured with kits from CELM.

Plasma ethanol determination. Rats were anesthetized, and blood samples were collected from the tail vein with heparinized syringes and centrifuged to obtain plasma. Blood samples were collected early in the morning immediately after the lights were turned on and ethanol concentration was measured with a kit from Sigma (St. Louis, MO, USA).

All values are reported as means \pm SEM. Multiple comparisons were performed by analysis of variance (ANOVA) followed by the Student-Newman-Keuls post hoc test. When only two groups were compared, the unpaired Student $t$-test was used.

Body weight gain and total calorie intake of ethanol-treated rats. The mean values of body weight gain during the 4 weeks of treatment (Table 1) were similar in control and $0.5,1.5,3$ and $7 \%$ ethanol rats. However, the $4.5 \%$ ethanol rats showed a lower body weight gain $(53.3 \pm 7.0 \mathrm{~g})$, which was significantly different $(\mathrm{P}<0.01)$ from the higher body weight gain observed in the $0.5 \%$ ethanol rats $(92.4 \pm 5.0 \mathrm{~g})$.

Higher dosages of ethanol in the drinking water resulted in a reduction of daily food consumption of $17 \%$ ( $3 \%$ ethanol, $\mathrm{P}<0.05$ ), $30 \%$ (4.5\% ethanol, $\mathrm{P}<0.001)$ and $18 \%(7 \%$ ethanol, $\mathrm{P}<0.01)$ when compared with control and $0.5 \%$ ethanol (Table 1 ); however, this finding clearly reflects the response of the rats to the additional calories in the drinking water $(0.7 \mathrm{~kJ} / \mathrm{ml}, 3 \%$ ethanol; $1.05 \mathrm{~kJ} / \mathrm{ml}$,
$4.5 \%$ ethanol, and $1.64 \mathrm{~kJ} / \mathrm{ml}, 7 \%$ ethanol). By combining the calories of the ethanol in the drinking water consumed with the calories of the standard chow diet eaten, the data obtained indicate that the total calorie intake per day of 3 and $7 \%$ ethanol rats was similar to that observed in control rats (Table 1). Differently, in the $4.5 \%$ ethanol-treated rats the total calorie intake per day was reduced $(\mathrm{P}<0.001)$ compared to all other groups (Table 1).

Ethanol-feeding affects Kitt during IVITT. After 4 weeks of treatment, the animals of all groups were submitted to an IVITT, and the results are shown in Figure 1A. The response of the rats treated with ethanol concentrations of $0.5,1.5$ and $7 \%$ in the drinking water yielded a Kitt value similar to that determined for the control rats, indicating the same insulin sensitivity for these animals. However, 3\% ethanol in the drinking water clearly altered the response of the rats, resulting in an increased Kitt value [5.41 \pm 0.39 (3\% ethanol) vs $4.13 \pm 0.21$ (control), $3.71 \pm 0.27$ (0.5\% ethanol) and $3.94 \pm 0.50 \% /$ $\min (7 \%$ ethanol); $\mathrm{P}<0.05$ vs 0.5 and $7 \%$ and $\mathrm{P}<0.01$ vs control, ANOVA]. The 1.5 and $4.5 \%$ ethanol-treated rats showed an intermediate response with an inverted U-shaped relationship between alcohol intake and in-

Table 1. Characteristics of Wistar rats treated without (control) or with different ethanol $(\mathrm{EtOH})$ concentrations $(0.5,1.5,3,4.5$ and $7 \%, \mathrm{v} / \mathrm{v})$ in the drinking water.

\begin{tabular}{lcccc}
\hline & $\begin{array}{c}\Delta \text { Body } \\
\text { weight }(\mathrm{g})\end{array}$ & $\begin{array}{c}\text { Food intake } \\
\text { (g/day) }\end{array}$ & $\begin{array}{c}\text { Fluid intake } \\
(\mathrm{ml} / \text { day })\end{array}$ & $\begin{array}{c}\text { Calorie intake } \\
(\mathrm{kJ} / \text { day })\end{array}$ \\
\hline Control & $74.5 \pm 3.7$ & $23.5 \pm 0.7$ & $37.9 \pm 0.9$ & $265 \pm 4$ \\
$0.5 \% \mathrm{EtOH}$ & $92.4 \pm 5.0$ & $24.4 \pm 0.9$ & $36.5 \pm 0.7$ & $282 \pm 6$ \\
$1.5 \% \mathrm{EtOH}$ & $85.8 \pm 12.4$ & $21.8 \pm 0.2$ & $40.6 \pm 1.3$ & $257 \pm 3$ \\
$3 \% \mathrm{EtOH}$ & $80.1 \pm 7.9$ & $19.9 \pm 0.8^{*}$ & $31.7 \pm 0.9^{\#}$ & $255 \pm 10$ \\
$4.5 \% \mathrm{EtOH}$ & $53.3 \pm 7.0^{\S}$ & $16.7 \pm 0.3^{* *}$ & $28.2 \pm 1.2^{\#}$ & $201 \pm 4^{+}$ \\
$7 \% \mathrm{EtOH}$ & $67.8 \pm 2.9$ & $19.7 \pm 0.3^{*}$ & $29.9 \pm 0.6^{\#}$ & $278 \pm 3$
\end{tabular}

Delta body weight is the difference between final (after 4 weeks treatment) and initial body weight. Data are reported as means \pm SEM for 26 control animals, and for 6 to 12 animals from each ethanol-treated group. Food, fluid and calorie intake were measured during the 4 weeks of treatment (2 measurements per week).

${ }^{\S} \mathrm{P}<0.01$ vs $0.5 \% \mathrm{EtOH} ;{ }^{*} \mathrm{P}<0.05,{ }^{*} \mathrm{P}<0.01,{ }^{*} * \mathrm{P}<0.001$ vs control and $0.5 \% \mathrm{EtOH}$; ${ }^{\#} \mathrm{P}<0.05$ vs control, 0.5 and $1.5 \% \mathrm{EtOH} ;{ }^{+} \mathrm{P}<0.001$ vs control, $0.5,1.5,3$ and $7 \% \mathrm{EtOH}$ (ANOVA, Student-Newman-Keuls post hoc test). 
sulin sensitivity, confirming that high ethanol consumption was not able to improve insulin sensitivity.

Consumption of $3 \%$ ethanol induces enhanced insulin sensitivity during the IVGTT. To confirm that $3 \%$ ethanol in the drinking water can induce ethanol-enhanced insulin sensitivity, additional animals were used for an IVGTT after 4 weeks of treatment (Figure 1C). Control and 3\% ethanol-treated rats showed the same plasma glucose profile during the IVGTT, and the calculation of the AUC revealed almost identical values $(6335.9 \pm 413.5$ for control vs $6335.5 \pm$ 414.8 for $3 \%$ ethanol). However, the glucose challenge caused a different profile of plasma insulin for control and ethanol-treated rats. As shown in Figure 1C, the AUC (375.5 \pm 39.3 for the control vs $245.2 \pm 30.4$ for $3 \%$ ethanol; $\mathrm{P}<0.05$ ) revealed that $35 \%$ less insulin was necessary for the $3 \%$ ethanol group to have the same clearance of glucose from plasma, indicating the higher insulin sensitivity of these animals.
Consumption of $3 \%$ ethanol induces low plasma ethanol levels without causing hepatic injury. Plasma ethanol levels were measured in all groups of animals (Figure 1B) in blood samples obtained early in the morning, a time when the animals were thought to have the highest plasma levels, considering that the drinking behavior occurs mainly at night. The plasma ethanol level was undetectable in rats receiving $0.5 \%$ ethanol, and progressively increased in rats treated with 1.5 to $7 \%$ ethanol. The plasma concentration of $3 \%$ ethanol-treated rats was $0.033 \pm 0.004 \mathrm{~g} / 100 \mathrm{ml}(0.028 \mathrm{~g} / 100 \mathrm{ml}$ in whole blood), which is considered to be a very low concentration.

Treatment with 3\% ethanol in the drinking water for a total period of 4 weeks did not result in hepatic injury (Figure 1D). At this time point, the control rats showed a plasma AST activity of $67.17 \pm 1.20 \mathrm{U} / 1$ and an ALT activity of $51.39 \pm 0.66 \mathrm{U} / 1$, while the ethanol-treated rats had activities of $71.90 \pm 5.63$ and $43.66 \pm 6.44 \mathrm{U} / 1$, respectively.
Figure 1. A, Inverted U-shaped relationship between the rate constant for plasma glucose disappearance (Kitt) during an intravenous insulin tolerance test and ethanol (EtOH) intake. B, Plasma ethanol concentration observed in Wistar rats receiving drinking water with $0.5,1.5,3,4.5$ and $7 \%(v / v)$ EtOH after 4 weeks of treatment. $C$, Area under the curve (AUC) of plasma glucose and insulin during an intravenous glucose tolerance test. $D$ Plasma aspartate aminotransferase (AST) and alanine aminotransferase (ALT) activities in rats receiving drinking water without (control) or with $3 \%$ $\mathrm{EtOH}$. Data are reported as means \pm SEM. ${ }^{*} \mathrm{P}<0.05$ vs 0.5 and $7 \% \mathrm{EtOH}$ (ANOVA); ${ }^{\mathrm{P}}<0.01$ vs control (ANOVA); ${ }^{+} \mathrm{P}<0.05$ vs control (Student $t$-test).
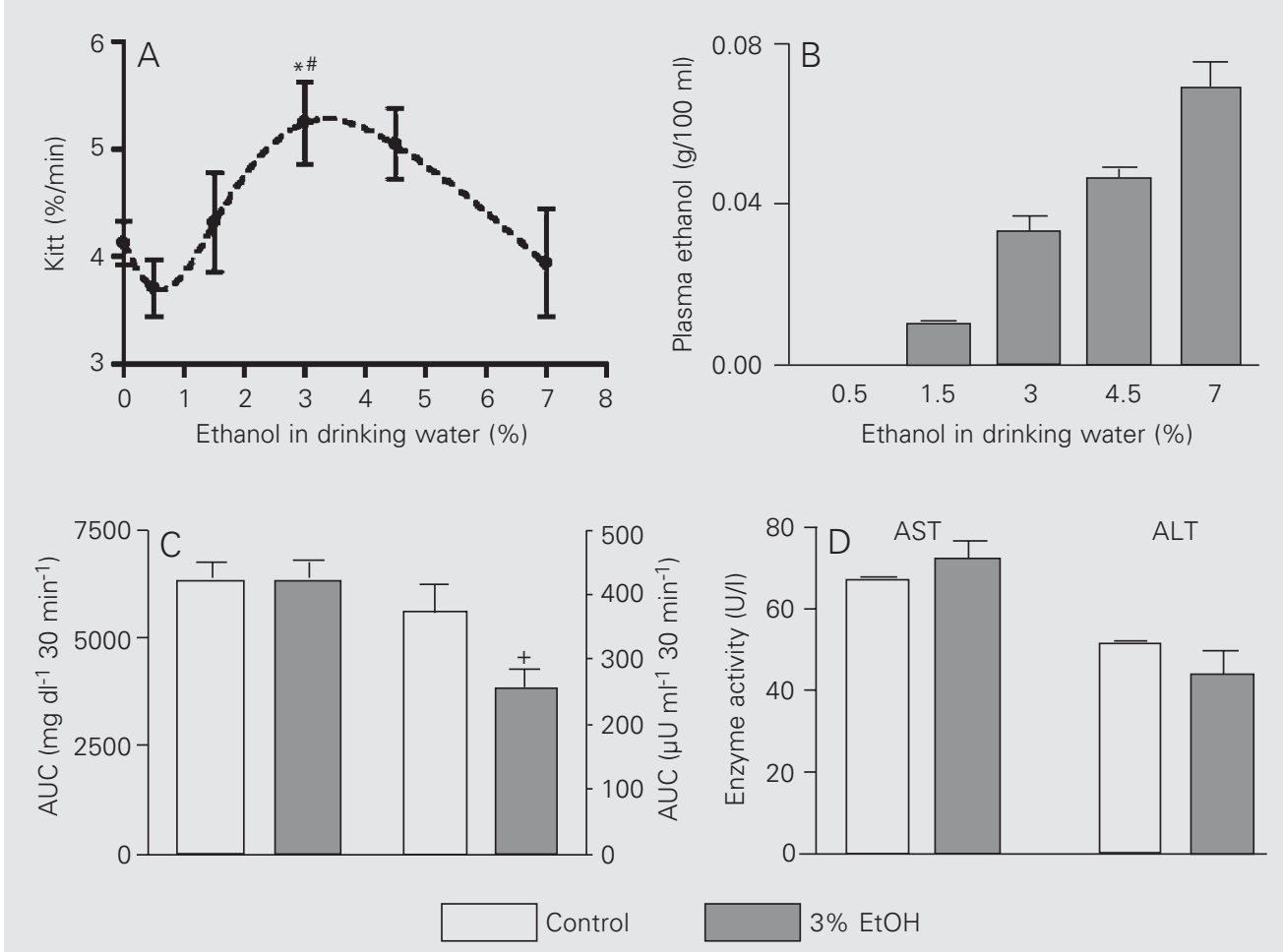
In the present study, chronic treatment of male Wistar rats with 3\% (v/v) ethanol in the drinking water over a period of 4 weeks resulted in enhanced insulin sensitivity, while lower or higher concentrations of ethanol in the drinking water had no such effect. This finding strongly supports the idea proposed in some human studies of an inverse Ushaped relationship between alcohol intake and insulin sensitivity $(12,14,15)$. However, it is reasonable to assume that at higher alcohol concentrations the inverse U-shaped relationship changes to an inverse J-shaped relationship since other human and animal studies have demonstrated that ethanol consumption can impair insulin-mediated glucose uptake and cause insulin resistance (17-19).

The consequence of both inverse U- and $\mathrm{J}$-shaped relationships is that only a certain range of alcohol can improve insulin sensitivity, and it will be interesting to determine if the applied ethanol concentration (3\% ethanol in the drinking water, equivalent to $9 \%$ of total calories) also has an effect on CHD risk factors like LDL cholesterol, fibrinogen and HDL cholesterol. This idea is supported by another study (20) in which SpragueDawley rats were fed a liquid diet containing 9\% ethanol as total calories and showed cardiovascular protection after several weeks of treatment.

It is important to note that improvement of insulin sensitivity was achieved in normal non-obese rats, in which glucose homeostasis is strongly controlled. Although 3\% ethanol treatment for 4 weeks induced a slight reduction in food consumption, the total calorie intake was unchanged, a fact that may be responsible for the preserved body weight. The absence of weight loss indicates that low ethanol consumption is the main factor responsible for the improvement of insulin sensitivity. Recovery of insulin sensitivity induced by ethanol treatment was reported in severely obese insulin-resistant mice, which, however, showed an important weight loss (20). Additionally, the $20 \%(\mathrm{v} / \mathrm{v})$ ethanol used (20) was a very high dose, as shown by the blood ethanol levels of the animals which were 2.5 times higher than the $3 \%$ ethanol levels observed in the present study. The low ethanol consumption by 3\% ethanol-treated rats had no effect on ALT or AST enzyme activity, suggesting preserved liver function and reinforcing the idea of a direct action of ethanol on the mechanisms involved in insulin sensitivity.

We showed that low ethanol consumption can improve insulin sensitivity, which is not related to the loss of weight. Clarifying these details will not only shed light on the phenomenon of ethanol-enhanced insulin sensitivity, but the identification of the involved mechanism(s) will also give an idea if the relevant pathway can be triggered by a drug, thus offering a possible option for a new treatment of diabetes.

\section{References}

1. Doll R (1997). One for the heart. British Medical Journal, 315: 1664 1668.

2. Kannel WB \& Ellison RC (1996). Alcohol and coronary heart disease: the evidence for a protective effect. Clinica Chimica Acta, 246: 5976 .

3. Criqui MH (1996). Alcohol and coronary heart disease: consistent relationship and public health implications. Clinica Chimica Acta, 246: 51-57.

4. Rimm EB, Giovannucci EL, Willett WC, Colditz GA, Ascherio A, Rosner B \& Stampfer MJ (1991). Prospective study of alcohol consumption and risk of coronary disease in men. Lancet, 338: 464-468.

5. Klatsky AL, Armstrong MA \& Friedman GD (1992). Alcohol and mortality. Annals of Internal Medicine, 117: 646-654.

6. Doll R, Peto R, Hall E, Wheatley K \& Gray R (1994). Mortality in relation to consumption of alcohol: 13 years' observations on male British doctors. British Medical Journal, 309: 911-918.

7. Preedy VR \& Richardson PJ (1994). Ethanol induced cardiovascular disease. British Medical Bulletin, 50: 152-163.

8. Gaziano JM, Hennekens CH, Godfried SL, Sesso HD, Glynn RJ, Breslow JL \& Buring JE (1999). Type of alcoholic beverage and risk of myocardial infarction. American Journal of Cardiology, 83: 52-57.

9. Kiechl S, Willeit J, Poewe W, Egger G, Oberhollenzer F, Muggeo M \& Bonora $E$ (1996). Insulin sensitivity and regular alcohol consumption: large, prospective, cross sectional population study (Bruneck 
study). British Medical Journal, 313: 1040-1044

10. Facchini F, Chen YD \& Reaven GM (1994). Light-to-moderate alcohol intake is associated with enhanced insulin sensitivity. Diabetes Care, 17: $115-119$

11. Van de Wiel A (1998). Alcohol and insulin sensitivity. Netherlands Journal of Medicine, 52: 91-94.

12. Lazarus R, Sparrow D \& Weiss ST (1997). Alcohol intake and insulin levels. The normative aging study. American Journal of Epidemiology, 145: 909-916.

13. Valmadrid CT, Klein R, Moss SE, Klein BE \& Cruickshanks KJ (1999). Alcohol intake and the risk of coronary heart disease mortality in persons with older-onset diabetes mellitus. Journal of the American Medical Association, 282: 239-246.

14. Razay G \& Heaton KW (1997). Moderate alcohol consumption has been shown previously to improve insulin sensitivity in men. British Medical Journal, 314: 443-444.

15. Bell RA, Mayer-Davis EJ, Martin MA, D'Agostino Jr RB \& Haffner SM (2000). Associations between alcohol consumption and insulin sensitivity and cardiovascular disease risk factors: the insulin resistance and atherosclerosis study. Diabetes Care, 23: 1630-1636.
16. Bonora E, Moghetti P, Zancanaro C, Cigolini M, Querena M, Cacciatoni V, Corgnati A \& Muggeo M (1989). Estimates of in vivo insulin action in man: comparison of insulin tolerance tests with euglycemic and hyperglycemic glucose clamp studies. Journal of Clinical Endocrinology and Metabolism, 68: 374-378.

17. Shelmet JJ, Reichard GA, Skutches CL, Hoeldtke RD, Owen OE \& Boden G (1988). Ethanol causes acute inhibition of carbohydrate, fat and protein oxidation and insulin resistance. Journal of Clinical Investigation, 81: 1137-1145.

18. Yki-Jaervinen H \& Nikkila EA (1985). Ethanol decreases glucose utilization in healthy men. Journal of Clinical Endocrinology and Metabolism, 61: 941-945.

19. Binsack R, White CR, Darley-Usmar V, Foster C, Zhou F \& Parks DA (1999). Chronic moderate alcohol consumption results in induction of nitric oxide synthase and cardiovascular protection. Free Radical Biology and Medicine, 27: S72 (Abstract).

20. al Qatari M, Shih MF \& Taberner PV (1996). Chronic ethanol consumption ameliorates the maturity-onset diabetes-obesity syndrome in CBA mice. Alcohol and Alcoholism, 31: 89-99. 